following: in our subjects, a period of 30 minutes was permitted after passage of the nasogastric tube before sampling started, there was no balloon impacted in the pylorus, we deliberately did not instruct the patient to spit out rather than swallow his saliva (because in our experience this factor encourages salivation and the swallowing of saliva), and we did not incubate the gastric juice samples with trasylol.

On the basis of three of the four studies they quote (reference 4 is irrelevant to this subject), they assume that their techniques are right and that ours are wrong. Three against one is hardly statistical significance. Is it possible that the rocks are in their court?

$M$ HOBSLEY Department of Surgery, UCLMS, Charles Bell House, 67-73 Riding House Street, London W1P $7 L D$

\section{Helicobacter pylori infection density and gastric inflammation in duodenal ulcer and non-ulcer subjects}

EDITOR,-Without an explicit quantification of the sensitivity of bacterial culture, and prevalence of $H$ pylori infection in the population from which their subjects were derived, Khulusi et al would not be justified in utilising culture positivity as a criterion either for 'ruling in', or for 'ruling our' $H$ pylori related gastritis (Gut 1995; 37: 319-24). Although the $100 \%$ specificity of bacterial culture confers a $100 \%$ positive predictive value for the diagnosis of $H$ pylori related gastritis, sensitivity can vary from $70-95 \%,{ }^{1}$ and the resulting reduction in negative predictive value would, in turn, be correlated with the prevalence of $H$ pylori infection in the community. Only the absence of histological stigmata of type $B$ gastritis yields a $100 \%$ negative predictive value for the diagnosis of $H$ pylori related gastritis. ${ }^{2}$

O M P JOLOBE Tameside General Hospital, Fountain Street, Ashton under Lyne, Lancashire OL6 9RW

1 Fennerty MB. Helicobacter pylori. Arch Intern Med 1994; 154: 721-7.

2 Cutler AF, Havstad S, Chen KMA, et al. Accuracy of invasive and non invasive tests to diagnose Helicobacter pylori

Gastroenterology 1995; 109: 136-41.

\section{BOOK REVIEW}

Clinician's Guide to Helicobacter pylori. By J Calam. (Pp 182; illustrated; $£ 39.50$.) London: Chapman \& Hall, 1996. ISBN 0-412-74000-1.

By any standard, the English language is a pretty remarkable implement, yet it is not without its limitations. There are certain words in other tongues (such as schadenfreude, chutzpah) that are without an English counterpart so that they have entered our common usage - and now even feature in the Oxford English Dictionary. Undoubtedly, Dr Johnson had other ideas about what sort of words might find themselves in an English dictionary. Perhaps we urgently need an Anglo-Saxon equivalent of the Academie Francaise to protect the language.

Another limitation to our native tongue is its fairly limited range of superlatives. I suspect this is a reflection of the traditional British tendency of understatement (which clearly has not been exported across the Atlantic). So limited is the conventional language in this respect that phrases of generous appreciation can seem so restrained that even a very positive critique may seem to be damning with faint praise.

Both these problems came to my mind in composing this review. Surely, chutzpah is just about the only word that gets anywhere near describing the manner in which Barry Marshall persisted in convincing the largely sceptical world of his ideas. The man seemed almost unbearable at times yet he has been proved right and only the most curmudgeonly would deny him his rewards (be they in this world or the next). The problem of finding appropriate words of praise confronts the reader of John Calam's book. Quite simply, it is the finest monograph in gastroenterology that I have encountered.

The evolving story of Helicobacter pylori must be familiar to most of this journal's readers. In a specialty that has changed much more dramatically in 30 years than any other within medicine, the $H$ pylori tale is about as dramatic as medical sagas get. Perhaps it is a good 'acid test' of Calam's book that he unravels the mysteries of the organism with a freshness and clarity that, as near as it is possible to be for a medical text, this book is 'unputdownable'. Aside from his clarity of prose, the book is interlaced with sparkling good humour. We all knew that being a gastroenterologist is a risk factor for carrying $H$ pylori. Maybe you were unaware that being a submariner also carries a risk. However, you will have to buy the book to learn about the putative mechanism (suffice it to say, it has something to do with flushing toilets and barometric pressure).

In the best traditions of medical teaching in the UK, the book is stuffed full of anecdotes, which makes it end to end readable. However, it is also very academic in the truest sense of the term. Competing hypotheses are discussed intelligently, areas of uncertainty are allowed to remain uncertain, and the book is massively referenced. If the Grand Inquisition were to return to Europe, I feel its most effective weapon of torture against a gastroenterologist would be not the rack but a cell furnished just with a chair (or, especially for us, a stool) in which the only reading matter would be all the abstracts ever written on $H$ pylori. Many of us would willingly confess to virtually any crime within a few hours. No one should ever be asked to write a comprehensive systematic review on $H$ pylori. Yet, Calam works from an extensive reference base and is always clear and never didactic except at the end where, sadly, he has failed to resist the temptation to provide algorithms for clinical management. Let's be fair and place the blame on his publishers for this error of judgement.

There are so many vested interests in the wonderful world of $H$ pylori. The pharmaceutical industry is fighting for its particular drug combination to be the numero uno in eradication. The epidemiologists have had their say but just what is to be done about the $H$ pylori carrier who carries a cancer risk - we will need the answer well before we get results from prospective studies. There is much important work to be done in the laboratory particularly to explain causation of $H$ pylori-linked disease ... and so forth. The clinician would also like some guidance from the great and good as to management guidelines. There have been helpful ex cathedra consensus statements from the USA. Yet there have not been clear guidelines from the United Kingdom, which many gastroenterologists would dearly welcome, particularly in their negotiations with the authorities that purchase health care for British citizens. Surely, we should be offering patients with such an incredibly common condition as dyspepsia a comparable standard of clinical service throughout this country. It is otherwise difficult to understand the meaning of the term 'National Health Service'.

Calam says everything a clinician should know about the most interesting bacterium to have turned up for many years. Several small books on $H$ pylori have appeared in the recent past. This is a veritable giant among them.

IAN FORGACS

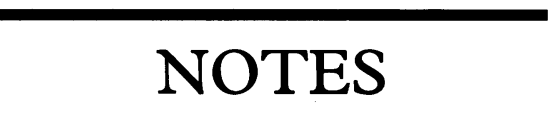

\section{Crohn's disease}

The Colitis and Crohn's Week will be held on 15-22 June 1996. The aims for the week are to increase awareness of colitis and Crohn's disease and their effects on people's lives. Further information from Richard Driscoll, Director of National Association for Colitis and Crohn's Disease, PO Box 205, St Albans, Herts AL1 1 AB. Tel: 01727 844296.

\section{Liver disease}

The XXIst International update on Liver Disease will be held at the Royal Free Hospital School of Medicine, London on 4-6 July 1996. For further details and information: Professor Neil McIntyre, University Department of Medicine, Royal Free Hospital, Pond Street, London NW3 2OG. Tel: 0171-794 0500 Ext: 3969; Fax: 0171 8302321. 